\title{
Discounting and life cycle assessment: a distorting measure in assessments, a reasonable instrument for decisions
}

\author{
S. Lueddeckens ${ }^{1} \cdot$ P. Saling ${ }^{2} \cdot$ E. Guenther ${ }^{3}$
}

Received: 13 November 2020 / Revised: 12 February 2021 / Accepted: 31 May 2021 / Published online: 28 July 2021

(c) The Author(s) 2021

\begin{abstract}
Although the weighting of environmental impacts against each other is well established in life cycle assessment practice, the weighting of impacts occurring at different points in time is still controversial. This temporal weighting is also known as discounting, which due to its potential to offend principles of intergenerational equity, is often rejected or regarded as unethical. In our literature review, we found multiple disputes regarding the comprehension of discounting. We structured those controversial issues and compared them to the original discounted utility model on which discounting is based. We explain the original theory as an intertemporal decision instrument based on future utility. We conclude that intertemporal equity controversies can be solved if discounting is applied as an individual decision instrument, rather than as an information instrument, which could underestimate environmental damages handed to future generations. Each choice related to discounting —-including whether or not to discount, or to discount at a rate of zero-should be well-founded. We illustrate environmental decision-related problems as a multidimensional issue, with at least three dimensions including the type of impact and spatial and temporal distributions. Through discounting framed as a decision instrument, these dimensions can be condensed into an explicit result, from which we can draw analogies to both weighting in life cycle assessment and financial decision instruments. We suggest avoiding discounting in environmental information instruments, such as single-product life cycle assessments, footprints, or labels. However, if alternatives have to be compared, discounting should be applied to support intertemporal decisions and generate meaningful results.
\end{abstract}

Keywords Life cycle assessment $\cdot$ Discounting $\cdot$ Temporal issues $\cdot$ Time $\cdot$ Discounted utility

\section{Introduction}

In environmental decisions, there are often trade-offs made between alternatives with immediate environmental impacts or impacts which are experienced in a more delayed fashion. The most important tool for environmental assessments

Editorial responsibility: Samareh Mirkia

S. Lueddeckens

ema@mailbox.tu-dresden.de

1 Chair of Business Management, Esp. Sustainability Management and Environmental Accounting, Technische Universität Dresden, 01062 Dresden, Germany

2 BASF SE, Corporate Sustainability, Carl-Bosch-Strasse 38, 67056 Ludwigshafen am Rhein, Germany

3 Institute for Integrated Management of Material Fluxes and of Resources (UNU-FLORES), United Nations University, Ammonstrasse 74, 01067 Dresden, Germany of products and processes is life cycle assessment (LCA), defined by ISO 14040 and 14044 . The weighting of different environmental impact categories is well established in life cycle assessments, whereas the weighting of impacts experienced in different times-also called discounting - is still under debate. Discussions about the implementation of discounting in LCA began in the early 1990s (Fearnside 2002b). Discounting is controversial because it could offend the principle of sustainable development, defined as "Development that meets the needs of the present without compromising the ability of future generations to meet their own needs" (Held 2016), in a way that future generations' rights are not given the same weight as the present generation. In the following, we will summarize LCA literature regarding the topic of discounting, contrast that with the original discounting theory, highlight the differences, and conclude with how to apply discounting in LCA contexts. The assessed literature represents the state of knowledge in 
scientific, English literature in December 2018, with some limitations mentioned below.

\section{Observations on the understanding of discounting in LCA literature}

Hellweg et al. (2003) provided an overview of the scientific discussion around the reasons for and effects of discounting in LCA. They provided a key publication for discounting in LCA which is still considered the most extensive in the field. They recognized that an anthropocentric view of the environment is necessary to be able to assess the temporal dimension of LCA. They further argued that weighting in general should not be perceived as unethical and drew a parallel between the weighting of different damage types and the weighting of damages which occur at different times. After a thorough review of the LCA literature, seven observations about the perception of discounting could be made:

\section{Discounting and setting time horizons are equivalent measures when attempting to limit the consideration of future impacts in an LCA}

According to Fearnside (2002b), in the early days of LCA, it was discussed whether to apply a discounting function or a fixed time horizon in the assessment of global warming potentials to express the constraint to only a foreseeable future. The time-horizon idea won because of its supposed simplicity. The idea that discounting would be an equivalent measure to setting time horizons for expressing a limited consideration of future impacts is very common in LCA literature (Fearnside et al. 2000; Boucher 2012; Almeida et al. 2015; Hu 2018; Mallapragada and Mignone 2017). For Hellweg et al. (2003), time horizons, i.e. temporal cut-offs, are a special case of discounting with a zero rate before the time horizon's end and an infinite rate after the time horizon.

\section{Discount functions and rates are arbitrary}

Discounting functions and rates are regarded as a non-consensual (Almeida et al. 2015), value-laden (Brandão and Levasseur 2010), and ethical (Levasseur et al. 2012) choice. Most publications apply a standard exponential discount function that is regularly applied in financial mathematics [e.g. Hellweg et al. (2003) and Yuan et al. (2009)]. The discount factor (DF) that is multiplied with the impact of year $t$ is calculated in the following way:

$\mathrm{DF}=\frac{1}{(1+r)^{t}}$

with $r$ being the discount rate. The overall impact is the sum of the yearly, discounted impacts:

Impact $=\sum_{t}\left(\right.$ Impact $\left._{t} \times \mathrm{DF}_{t}\right)$

In a systematic review (Lueddeckens et al. 2020), it was found that discounting is not regularly applied in LCA studies and, if so, then in a defensive way by presenting scenario or sensitivity analyses. Yuan et al. (2009) stated "Although we recognize the need to develop proper discounting methods, such endeavours deserve a more thorough analysis". There is no consensus on whether to apply discounting and, if so, on which discount function. However, discounting can have a significant influence on LCA results. This can be illustrated by the examples for the application of discounting in a rather short term by Yuan et al. (2009) (Fig. 1) and in a rather long term by Hellweg et al. (2003) (Fig. 2).

The comparison of Figs. 1 and 2 clearly demonstrates the dynamics of exponential functions. In the car example (Fig. 1), the application of a $1 \%$ discount rate results in nearly no difference compared to the $0 \%$ rate, while in the landfill example (Fig. 2) with a long time horizon, the impact is discounted to an almost negligible amount with the $1 \%$ rate. When leaching of the landfill starts to intensify after 1000 years, the DF has already shrunk to 0.00005 . Even the seemingly low rate
Fig. 1 Global warming potential of a middle class car in $\mathrm{kg}_{\mathrm{CO} 2 \mathrm{eq}}$ according to Yuan et al. (2009) over 11 years, discounted at 0 , 1 , and $10 \%$, showing the net present values (NPV) of the emissions

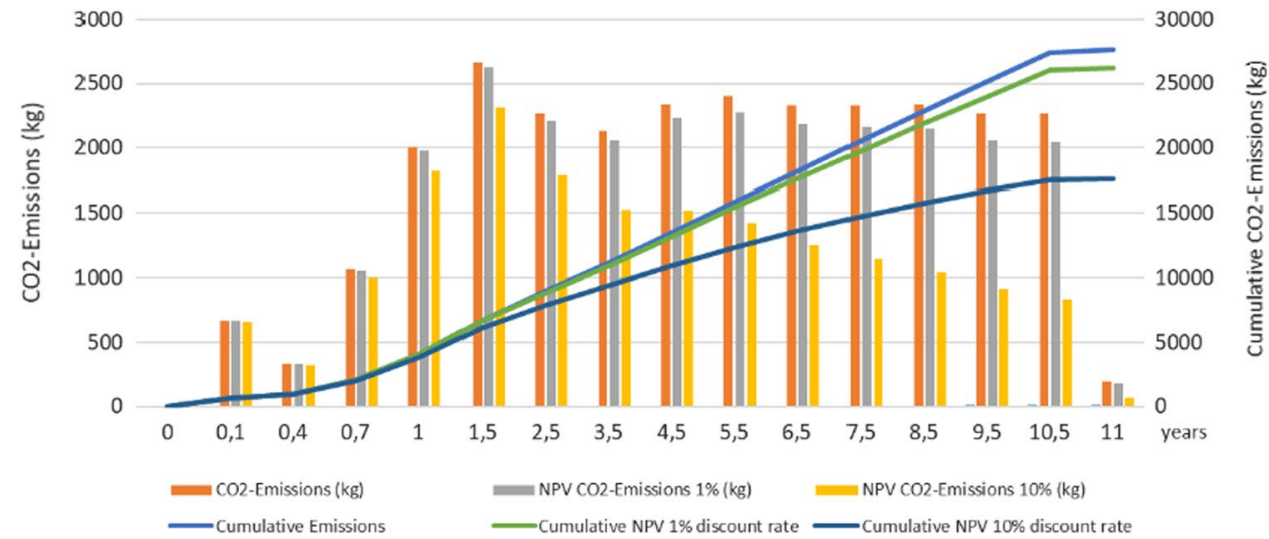




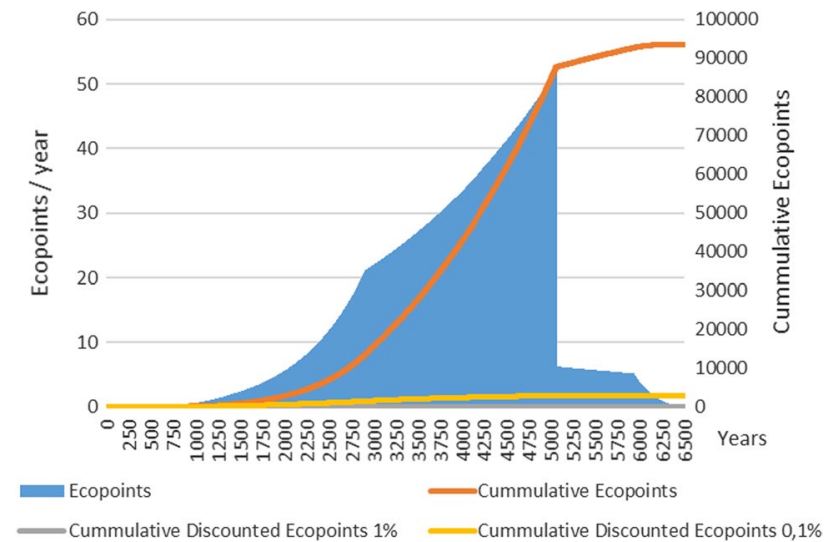

Fig. 2 Ecopoints of a heavy metal leaching landfill according to Hellweg et al. (2003), discounted at $0,0.1$, and $1 \%$

of $0.1 \%$ marginalizes the weight of the impact over a long time horizon. However, the use of a $10 \%$ discount rate, which would be in the range of equity costs of private companies, already leads to a $36 \%$ decline of the weight of assessed emissions in the car example. As environmental damages not only harm companies responsible for their occurrence, but actually all of society (as external costs), the application of the social discount rate is proposed (Richards 1997; Wang et al. 2018). This rate represents the expected capital costs of public projects and is usually lower than a private discount rate because society has a longer time horizon and less time preference than individuals. Bakas et al. (2015) propose a small rate near 0\% as the rate is very decisive. According to Yuan et al. (2009), discounting should be handled very conservatively because an underestimation of impacts would be more critical than an overestimation.

\section{Discounting is a measure for changing background concentrations and, therefore, changing impact characterization and normalization}

Hellweg et al. (2003) explain discounting in a monetary way. Changes in the price level, i.e. the consideration of inflation and deflation in economics, are translated to an increasing or decreasing background concentration of pollutants. This is important because many impacts depend on doses or threshold values. For example, soil has a certain buffer for acidic substances until exhaustion occurs. This idea of Hellweg et al. (2003), which can be understood as a simplification of dynamic characterization and normalization, was also mentioned by Hellweg et al. (2005), but was later rejected by O'Hare et al. (2009). They called it "physical discounting" and stated "the discounting model applies to costs and benefits, not to physical phenomena that generate them, unless their economic value is otherwise stable over time".

\section{Uncertainty of emissions and impacts is a reason for discounting}

Discounting in order to reflect uncertainty takes into account that environmental damages might become more or less important in the future for uncertain reasons. For example, they would become less important if technologies are developed that reverse damages or that make it easier to live with them. The importance of environmental damage could rise if the number of affected people grows. Hellweg et al. (2003) concluded that these reasons are too weak to justify discounting. They argue that the possibility of the availability of damage-reducing technologies for future generations is not a justification for passing the problem on to them. Furthermore, calculating with future innovations already considered would reduce the incentives to develop them because LCA results would present a more optimistic outlook today. Uncertainty about whether future impacts will happen is also considered as a reason for discounting by Udo de Haes et al. (1999) and Yuan et al. (2009). This uncertainty results from technological advances or from the reduced life cycle of products, e.g. due to accidents. In contrast to that, Hellweg et al. (2003) proposed the consideration of uncertainty of impacts in the characterization phase of LCAs.

\section{Discounting can be applied if the impact can be monetized or if the impact and its monetary value are at least congruent}

If environmental damage is monetizable, the profitability of emission abatement measures can be calculated and tradeoffs can be made (Hellweg et al. 2003). If capital can be invested in a way that produces income which is higher than the rising environmental costs, then the environmental damage would be acceptable. So, environmental damage would lose its value given a growing economy and a growing productivity of capital. Rising wealth may enable people to cope with environmental damages or it might increase their willingness to pay for counter measures. On the other hand, the utility of more money might someday be less than the utility of an intact environment. In other words, there might be a diminishing marginal utility of consumption with that extra money that was earned with environmental damages as a side effect. Hellweg et al. (2003) criticized that it cannot be generally expected that future generations will be satisfied with monetary compensation for environmental damages or that compensation funds will actually be expended in the future in a way they were intended for. Fearnside et al. (2000) preferred the term "immediate emission equivalent" over discounted emissions because, in their opinion, the latter would only include economic reasons. The economic discount rate of emissions depends on the overall change in 
wealth and the change of the marginal utility of that change (Fearnside et al. 2000) and inflation (O'Hare et al. 2009; Levine et al. 2007). According to Kendall et al. (2009) and Wang et al. (2018), environmental impacts can be discounted in the same way as monetary values, even if there is currently no reliable monetization mechanism available for certain emissions. They presuppose that an impact and its monetary value are often congruent.

\section{"Discounting is the mechanism by which a value for time is normally translated into economic decision-making" (Fearnside et al. 2000)}

This quotation implies that time would have a value that needs to be assessed, instead of the events themselves which occur on the timeline. According to Fearnside et al. (2000), the value for time results in the preference for positive events in the near future (like consumption) and the expectation of wealth later. In other words, the "time value" of a positive impact declines if that event's position on the timeline moves to the future and if the expected wealth becomes lower in the future. On the other side, a negative impact becomes less important if it happens in the future and if the expectations for future wealth are high. Following this interpretation, environmental impact can be discounted absolutely, not just relative to alternatives.

\section{Discounting because of a time preference is unethical}

Pure time preference, according to Hellweg et al. (2003), means that the empirically evident preference of humans for earlier utility versus utility in a distant future. Nevertheless, they suggested time preference be disregarded in LCAs as this would be immoral and give future generations less value than current ones. However, time preference is the main motivation for discounting for other authors (Fearnside 2002a; Levine et al. 2007; O'Hare et al. 2009).

\section{Materials and methods}

It can be noted that a widely accepted theory of discounting in LCA does not exist up to now. Every aspect, such as reasons for discounting, influencing factors, kinds of functions, and their variables, lack consensus in the literature. In our opinion, there is some disagreement between what can be read in the literature about discounting in LCA and the original sense of discounting in social sciences. Therefore, a summary of the idea of discounting is provided and, subsequently, a comment on the ongoing debate, followed by what we derive to be the correct implementation for LCA practitioners.

The origin of discounting is a decision problem: there are several options with different temporal distributions of utility, meaning different kinds of costs and benefits. Scholars have been aware of this problem since John Rae's publication of "The Sociological Theory of Capital" in 1834. Building on Adams Smith's theory, according to which the wealth of nations is mainly "determined by the amount of labor allocated to the production capital" (Frederick et al. 2002), he argued that there must also be an "effective desire of accumulation" of wealth. That means there must be a desire to invest capital today for future returns. Rea first described the decision problem between immediate benefits from direct consumption of capital, e.g. for leisure activities, and future benefits of different investment options. He explained the desire psychologically. Reasons for waiting for future benefits are "generally accepted virtues" like self-restraint and social affections. Reasons against are the uncertain future and time preference, i.e. the preference for the immediate benefit.

These qualitative and moralized considerations were formalized by Irving Fisher in "The Theory of Interest" in 1930. Fisher proposed an interest rate at which two investment alternatives would be equal and he introduced the term "present value" of money. The interest rate was referred to as the "equalizing rate" (Illés 2014). Further, he divided influences on the decision into objective factors like uncertainty and economic growth and into personal factors (Frederick et al. 2002).

Fisher's model was only applicable between defined alternatives in defined timeframes. It was generalized by Paul Samuelson in "A Note on Measurement of Utility" in 1937 as the "Discounted Utility" model. In this model, an intertemporal evaluation of any investment can be made because all psychological, objective, and personal factors are combined in the "discount rate" (Frederick et al. 2002). Samuelson described the formula for the net present value (NPV) of investments which is generally applied today:

$U_{t}=\sum_{t=0}^{T}\left(\frac{1}{1+p}\right)^{t} \times u(t)$

$U_{t}$ is the intertemporal utility (the NPV), a sum of the instantaneous utilities $u(t)$ in the different time steps, e.g. different years, which must be multiplied with the relative weight in period $t$, derived by the discount rate $p$.

Samuel's formula can easily be applied to environmental impact because money is not discounted but rather utility in any kind: 


$$
I_{t}=\sum_{t=0}^{T}\left(\frac{1}{1+p}\right)^{t} \times i(t)
$$

$I_{t}$ is the intertemporal impact and $i(t)$ is the temporally distributed impacts, thereby equalizing a negative environmental utility. The idea of the equivalence of human made production capital and other capital that produces natural resources (e.g. timber or oxygen by a tree) and ecosystem services (e.g. water cleaning) is reflected by the concept of "natural capital" (Constanza and Daly 1992). Natural capital assessment and LCA are not fully congruent because the latter is a value-based decision instrument concerning the "areas of protection", e.g. including human health, but there are many intersections, especially in the possible application of discounting. Nevertheless, even without the concept of natural capital, the (dis-)utility of environmental impacts should be discounted in intertemporal decisions. The challenge is in deriving a suitable discount function. It is important to note that discounting, according to Paul Samuelson, must combine objective, external factors and individual, internal factors. For that reason, discounting is always highly individual and cannot be generalized for every case.

\section{Our understanding of discounting compared to LCA literature}

Based on the discounted utility theory, we can now comment on previously mentioned opinions about discounting in LCA that we found in the literature (summarized in Table 1).

\section{Assertion 1: discounting and settings time horizons are equivalent measures used to limit the consideration of future impact in LCA}

Discounting and time horizons follow a different logic. A time horizon is a temporal system barrier that should be defined in the goal and scope section of an LCA. Like other physical system barriers that exclude less important emissions or consequences (consequential LCA), time horizons could follow objective criteria or standards. The length of a time horizon can be derived from the duration of the impact, from approved political goals, or the urgency of environmental problems (Lueddeckens et al. 2020). There may still be reasons for individual time horizons, depending on goal and scope of a study, but a standardization is possible and widespread for most impact categories. Discounting, on the other hand, is highly individual and fully dependent on a decision maker's utility at different points in time. Standardization of discount rates is not possible. Discounting and time horizons are not equivalent and time horizons, in our opinion, are not simply a special case of discounting (Hellweg et al. 2003).

\section{Assertion 2: discount rates are arbitrary}

For the decision maker, the discount rate is not arbitrary-it just seems that way for the outsider who cannot follow the decision process with the individual influences. The outsider is not familiar with the opportunity costs. However, there is no framework for discounting of environmental impacts available, and without a basic underlying theory, a decision for a certain discount function might seem arbitrary. Thus,

Table 1 Comparison of assertions on discounting in the literature and our view on them

\begin{tabular}{lc}
\hline Assertions on discounting in the literature & Comments \\
\hline $\begin{array}{l}\text { Discounting and settings time horizons are equivalent measures used } \\
\text { to limit the consideration of future impact in LCA }\end{array}$ & $\begin{array}{c}\text { The time horizon is a system barrier, defined in goal and scope of an } \\
\text { LCA. Discounting is a tool for assessing individual utility in different } \\
\text { points in time. Both measures are not equivalent but each of them } \\
\text { must be considered }\end{array}$ \\
$\begin{array}{ll}\text { Discount rates are individual for the decision maker. From an outside } \\
\text { perspective, they might appear arbitrary if the opportunity costs are } \\
\text { unknown }\end{array}$ \\
$\begin{array}{l}\text { Discounting is a measure for changing background concentrations and } \\
\text { therefore changing impact characterization and normalization }\end{array}$ & $\begin{array}{c}\text { Discounting only assesses intertemporal utility, not physical processes. } \\
\text { The term is not supposed to be used in the context of dynamic charac- } \\
\text { terization or normalization }\end{array}$ \\
$\begin{array}{c}\text { Uncertainty of emissions and impacts is a reason for discounting } \\
\text { characterization before discounting }\end{array}$ \\
$\begin{array}{c}\text { Discounting can be applied if the impact can be monetized or if impact } \\
\text { and monetary value are at least congruent }\end{array}$ \\
$\begin{array}{c}\text { Monetization is no prerequisite for discounting. Any utility can be } \\
\text { discounted in intertemporal decisions }\end{array}$ \\
translated into economic decision-making \\
$\begin{array}{c}\text { Time is not evaluated in discounting but utility in different points in } \\
\text { time. This utility does not only depend on time, but also on other vari- } \\
\text { ables in the discount function }\end{array}$ \\
$\begin{array}{c}\text { Time preference is existent in any human decision process and does not } \\
\text { contradict an anthropocentric definition of sustainability }\end{array}$ \\
\hline
\end{tabular}


this assertion might describe the current situation of environmental discounting, but it would be wrong to assume that discounting cannot be applied in a non-arbitrary, wellfounded way. The key for developing a discounting framework is to accept the individuality of discounting and to overcome the idea of developing a general discounting function for every use case.

\section{Assertion 3: discounting is a measure for changing background concentrations and therefore changing impact characterization and normalization}

A changing background concentration or a changing sensitivity of the ecosystem should be modelled in a dynamic characterization (Herzog et al. 2003; Collinge et al. 2013; Bakas et al. 2015) and a dynamic normalization (Herrchen 1998; Cherubini et al. 2012). This issue is important but does not correspond to intertemporal decision making. We suggest to avoid the phrase "discounting" in this context, including the term "physical discounting" (O'Hare et al. 2009). According to the discounted utility theory, only utility, not physical things, can be discounted.

\section{Assertion 4: uncertainty of emissions and impacts is a reason for discounting}

We agree with Hellweg et al. (2003) that emissions should be modelled in the inventory and impact in the characterization. Uncertainty in these steps can be addressed through a Monte-Carlo analysis or other procedures. The application of discounting here would result in inappropriate "physical discounting". Uncertainty in LCA is in principle objective and general, discounting is subjective and individual. According to Arrow et al. (1996), there is general consensus in economics that uncertain risks should be transformed into "certain equivalents" before discounting them.

\section{Assertion 5: discounting can be applied if the impact can be monetized or if impact and monetary value are at least congruent}

Discounting is independent from monetary values. Every kind of utility can be discounted. Avoided negative impact is always a utility, and negative impact is always disutility. It is not wrong to assume that monetization would justify discounting, but it is not a prerequisite. Although there has been much progress in the field of monetization of environmental impacts, e.g. through the enactment of ISO 14008, there might be limits. Some environmental impacts are easier to monetize than others. For example, Macháč et al. (2021) monetized soil degradation by accounting the reduction of agricultural yield. They showed that a higher discount rate would result in less fertilization today because of the reduced utility of future yield. Current monetization methods might be ineffective in assessing global, irreversible, and critical damages (Temel et al. 2018). If prices cannot be observed on a free market, then the evaluation of environmental damages is influenced by personal bias and ideological considerations (Kallis et al. 2015). These issues do not affect discounting as long as the utility of environmental impact can be assessed in some way. The unit of measurement does not need to be money.

\section{Assertion 6: "discounting is the mechanism by which a value for time is normally translated into economic decision-making" (Fearnside et al. 2000)}

Discounting is a tool for intertemporal decision-making. It does not directly evaluate time, but rather the utility at different points in time. Time itself has no value in discounting if there is no alternative and, thus, no decision to be made. There are measures for evaluating time, like "real options" (Reuer and Tong 2007). These are based on the theory of financial options. A financial option securitizes the option to buy or sell a good, stock, future, or anything else on the market at a certain point in time in the future for a certain price. The price of such an option can be calculated according to the Black-Scholes model and consists of an inner value that is the difference between the value of the good and the securitized price in the option and the time value. A real option is an option for a real (non-financial) investment. That means, an individual or organization can decide to invest now or later in real goods like machines, new processes, or to use resources sooner or later. This option can be regarded as an opportunity cost of the same investment. The only difference is the point in time. For example, a forest owner can decide to harvest his wood now. Then, he would lose the option to harvest later when the wood price may be higher. A society can decide to use natural gas reserves now, but therefore loses the opportunity to use them later, e.g. when there may be little solar power to harvest because of a major volcanic eruption. Real options could be utilized to evaluate resource depletion, instead of the corresponding LCA impact categories. They contain value for time, while discounting does not. The difference between cumulated impact and discounted cumulated impact is not the time value, but the difference from the opportunities. This value is not constant but depends on the evaluated utility and personal criteria. Discounting in an absolute way without regarding individual alternatives would contradict with discounted utility theory. 


\section{Assertion 7: discounting because of time preference is unethical}

Time preference is the main idea behind discounting. In the standard theory, the discount rate is the sum of time preference and opportunity costs or utility of economic growth, respectively (Gowdy et al. 2013). Nevertheless, economic growth, the productivity of capital, or the marginal utility of consumption would not be interesting for an LCA practitioner if there was no time preference. Under such an assumption one would always invest capital and never consume (if possible), so without consumption there would be no benefit of an investment experienced. The generally accepted definition of sustainable development "Development that meets the needs of the present without compromising the ability of future generations to meet their own needs" (Held 2016) concedes a certain degree of time preference to the present generation. The ethical question arises in the exploitation of the LCA outcome and leads to the question of whether LCA should be measurement-oriented or action-oriented. This discussion was raised in literature in the determination of an adequate time horizon. An actionoriented LCA would have short time horizons so that actions produce an outcome and a clear responsibility for people living today. Nevertheless, a short time horizon incentivizes problem shifting to the future, after the considered time horizon. Although it is generally accepted that future generations should not be penalized, there are considerations that long THs marginalize effects of short-term actions, like carbon capture and storage (Herzog et al. 2003; Almeida et al. 2015). Especially an infinite TH would make every sequestration, if assessed with the GWP indicator, useless (Brandão et al. 2013), but would avoid problem shifting to the future (Lebailly et al. 2014). In our opinion, LCA should be measurement-oriented and therefore has a long TH. It should deliver neutral information that can be utilized in a decision instrument which is action oriented. Time preference should be expressed by discounting in the decision process, not by setting a short TH in the foregoing measurement process. If applied in that way, discounting would not be regarded as unethical but as reasonable.

\section{Discounting as part of a multidimensional decision tool}

Life cycle assessment (LCA) is a multidimensional information instrument and discounting is an important tool for reducing dimensions for decision processes. Information on environmental impact provided by LCA appears in at least three dimensions (Fig. 3).

One dimension is the impact type. For example, the "ReCiPe" tool includes 18 impact types, such as water

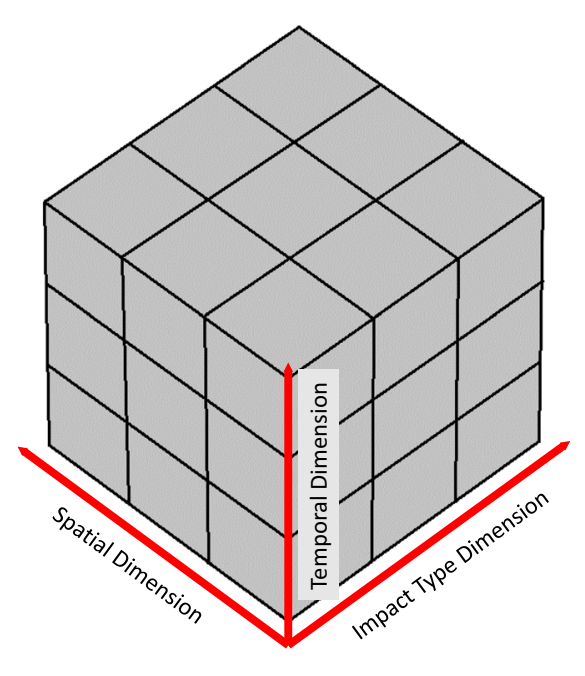

Fig. 3 LCA data are a 3-dimensional matrix. In this example, there are 3 impact types in 3 locations at 3 points in time, resulting in 27-dimensional information

depletion or terrestrial acidification (Huijbregts et al. 2017). Another dimension is the spatial one. Often, background concentrations that differ spatially have a significant influence on the impact. A comprehensive review (Patouillard et al. 2018) on the integration of the spatial dimension in LCA shows the importance of spatial information in every step in LCA, e.g. in defining a spatial system barrier for the assessment, in the choice of spatially fitting databases for the inventory, and suitable regional characterization factors. The third dimension is the temporal one. Emissions may occur in different points in time and their impact, as well as their weight for decision makers may change over time. The temporal dimension is a complex problem causing "temporal issues" in sustainability assessments and especially in LCA. In a systematic literature review (Lueddeckens et al. 2020), six direct temporal issues in LCA were identified: (1) time horizons of the assessment, inventory, and characterization, (2) the temporal resolution of the inventory, (3) time dependencies in the characterization functions, (4) time dependent benchmarks in the characterization, (5) time dependent weighting (changing weighting factors over time), and (6) temporal weighting-the weighting of future impacts in decision processes.

An LCA practitioner is highly interested in reducing these dimensions to only one score, so that alternatives can be easily compared. Fortunately, there are aids that help to reduce these dimensions. Tools like ReCiPe or Traci were developed to limit the complexity of information supplied by LCA by reducing the impact type dimension and, in part, the spatial dimension. The 18 impact types evaluated in ReCiPe are 
midpoint damages. That means they quantify the sources of damages that result from the inventory, for example, ionizing radiation that causes sickness. Through impact pathways, the impacts of several impact sources are aggregated to three endpoint impact, such as damage to human health. There is a fixed correlation between the midpoint and endpoint damage types (Huijbregts et al. 2017). As midpoint damages can cause multiple endpoint damages, there is a fixed factor for every midpoint damage in relation to an endpoint damage. Endpoint damage can be further aggregated by the application of weighting, an optional step in ISO 14040. For example, Eco-Indicator 99 is another assessment tool that aggregates further than ReCiPe (Goedkoop and Spriensma 1999). Here, the same three endpoint indicators are further aggregated to a single ecopoint score. This is performed by weighting human health and ecosystem quality by $40 \%$ each and resource depletion by $20 \%$. Hauschild et al. (2018) list approaches for weighting impact.

The spatial dimension is also addressed by ReCiPe by providing multiple midpoint characterization factors for different regions. Unless the spatial resolution of such CFs is low, there is a suitable way of assessing and aggregating the spatial dimension of LCA. Weighting factors must fit the stakeholders, too, and those can be widely distributed over the planet. If spatially differentiated weighting factors are available, the spatial information should be maintained until the weighting step. Sources for the development of spatially differentiated weighting factors could be polls, such as the MYWorld survey (United Nations 2015). Other sources could be cultural studies like Hofstede et al. (2010), Schwartz (2007), or Haidt (2013). Hofstede et al. (2010) found six major cultural dimensions and mapped the world according to them. Schwartz (2007) found three value dimensions that differentiate national cultures. Haidt (2013) identified five moral categories and categorized nations according to them. To our knowledge, no regionalized weighting factors are available for LCA up to now, but they may be developed in the future.

The temporal dimension can be aggregated analogically. While temporal issues of the inventory, characterization and normalization are technical issues that can be handled by measurements, simulations, statistical methods, or orientation on political emission targets, the choices of time horizons and discounting functions (temporal weighting) are value-based choices. The temporal distribution of emissions is currently aggregated in a very simple way. All inventory data inside the time horizon (TH) is simply summated without any differentiation in the temporal dimension. ReCiPe considers time in one variable- the cultural perspective. Three cultural perspectives were introduced by Hofstetter et al. (2000). According to this theory, societies can have the archetypes of fatalist (with the shortest TH), individualist, hierarchist, and egalitarian (with the longest
TH). LCA practitioners usually omit fatalist because fatalists would widely ignore future environmental concerns, which is not the purpose of LCA. In ReCiPe, the remaining three cultural perspectives result in different time horizons in which emissions are summed up. For example, in the calculation of climate change, the individualist has a 20 -year perspective, the hierarchist a 100 -year perspective, and the egalitarian considers an infinite time horizon. The cultural perspective in ReCiPe also counts for weighting factors. The individualist perspective is more optimistic on adaption to climate change than the egalitarian (Huijbregts et al. 2017). Nevertheless, the cultural perspective approach is a very strong simplification of the temporal dimension of LCA. Further, it is affected by the error of central tendency-a phenomenon known from social sciences (Landy and Conte 2016). Participants who are asked to make a rating on a given scale tend to put their rating rather in the middle than at the outer ranges of the scale. This also creates bias in surveys- the test persons are influenced by the given scale. In the LCA context that would mean people usually prefer the hierarchist view. Nevertheless, setting a TH only defines the extent of the temporal dimension which still needs to be aggregated for decisions. Here, discounting is the measure of choice, instead of simple summation. It can be regarded as temporal weighting of a decision maker. In contrast to weighting of damage types, where the affected stakeholders are in the focus, discounting focuses on the decision maker. The temporal dimension of LCA can be condensed to a single score, based on the utility of the temporally distributed impacts. Debates about the appropriate length of TH can be avoided by discounting. Time horizons as a temporal system barrier can still be defined in the goal and scope of an LCA, but they would no longer express individual factors as this is addressed by discounting. As a result, a distinct proposal for a decision could be made. Discounting would close the gap of methods for receiving a single LCA score which is easily comparable between alternative choices. If weighting of impact types is generally accepted in the LCA community, temporal weighting (discounting) could be accepted just as well. For this purpose, a discounting framework for environmental impact, based on the discounted utility theory, must be developed.

\section{Results and discussion}

In our opinion, the ongoing debate about whether to apply discounting or not in LCA has a straightforward answer. We suggest not to discount in assessments that have an informative character. In other words, we suggest not to discount in a single-product LCA, in product footprints, in assessments that are meant for environmental labels, and so on. Similarly, one would also not discount related financial data. 
For example, if someone buys a car, they will be interested in yearly costs for inspections or for the exchange of spare parts. Of course, these costs are not discounted because no seller knows the personal opportunity costs of the customer or their personal discount rate. The customer will also be informed about the $\mathrm{CO}_{2}$ emissions of the car. For the same reason, there is no sense in discounting them.

However, as the customer or the one who has to decide between different options, it is always rational to discount any utility in intertemporal decisions.

The reliance on different perceptions is also assumed by Field et al. (2001), who state that decisions on discount rates should be made in the end by the decision maker and not already by the LCA maker.

Making this clear separation, the debate between a more action-oriented LCA with high time preference and a more measurement-oriented LCA with little or no time preference would not exist. An informative LCA would always be purely measurement oriented. A decision instrument is always purely action oriented-the action is the decision. When discussing the aggregation of the environmental dimension through weighting (Huijbregts et al. 2017), we cited that this weighting should orientate on all stakeholders' interests. Decision instruments, with discounting as one of them, orientate on the decision maker.

Saurat et al. (2015) list 51 methods and 38 tools for sustainability assessments. It cannot always be defined which instrument is an information and which is a decision instrument. An LCA can be comparative for different products or just made for a single product, but in real decisions there is mostly also a financial dimension. Because of limited resources, the option with the best LCA results cannot always be chosen and the financial or other resources must be taken into account. Saurat et al. (2015) list 10 "hybrid" assessment methods that assess the environmental and financial/resource-based sustainability with eco-efficiency analysis being the most popular one. Standardized in ISO 14045 , eco-efficiency analysis is a portfolio model with an aggregated environmental dimension and an aggregated financial dimension. It is well-suited for discounting in both dimensions.

What would the consequences be of not discounting (or at a rate of zero) in intertemporal decisions? Our examples (Figs. 1, 2) show that discounting reduces the cumulative impact significantly, depending on the discount function. It is debatable if an exponential discounting function (Fig. 2) is the more appropriate function for very long time horizons or if, for example, a hyperbolic function would better reflect human decision making (Gowdy et al. 2013). In comparison to a non-discounted impact in example 1, a decision maker would attach greater value to low fuel consumption than to the recyclability of the car, which would make sense in the ecologic as well as economic perspective. The example of Macháč et al. (2021) shows the same idea from another perspective. Here, not the costs but rather the revenues play the most important role. Under low discounting, a farmer would invest more capital in maintaining the high quality of his soil because the future yield of the agricultural production has a high value for him; under high discounting, however, the immediate costs for fertilizers are given a higher value than the future yield. The control of parasites in agriculture would be a similar example. Control measures result in near-term costs which avoid long-term damage and yield reductions. Discounting of costs and benefits (external or internal) changes their ratio and leads to other decisions. Should a car manufacturer design a car and place a high priority on recyclability despite the fact that the first car owner usually sells the vehicle before it reaches the end of its life? Should a farmer invest significantly in his soil (which is often leased) so that the next generation of farmers may benefit? Those examples demonstrate how the disregard of discounting would lead to decisions from the perspective of the ivory tower, ignoring the social context and the affected people. Assuming the absence of time preference would mean to assume that investors have no interest in profiting from their investments during their life time, or that voters would accept laws that reduce their income for the promise of a benefit of future generations, without the ability to control the outcome of that measure and to make politicians responsible. It is not only unrealistic to presume such temporal indifference of people. Empirical evidence shows that there is an even higher personal discount rate of people compared to standard discount rates in business, resulting in hyperbolic discount rates. Through various examples, Gowdy et al. (2013) also show that time preference has an evolutionary advantage for humans and animals. Time preference leads people to act in order to receive benefits from their action in a time scale they can personally observe and influence. People react to incentives and those must be within their own reach. Further, assuming the absence of opportunity costs, the second variable in discounting, would mean to assume a limitless availability of goods or the complete fulfilment of human needs. The farmer of Macháč et al. (2021) could potentially invest in better machinery instead of fertilizers to improve his yield, but maybe he also wants to buy a new car (which is more or less recyclable). In a world of finite resources, every decision means to miss many opportunities, be it other environmental beneficial measures or benefits in other fields of interest for humans. For example, at a discount rate of zero, a company would have "surplus" money and be left with uncertainty regarding how to allocate it. The debate on whether to invest now in environmental beneficial measures or to wait until better technology could be acquired in higher quantities 


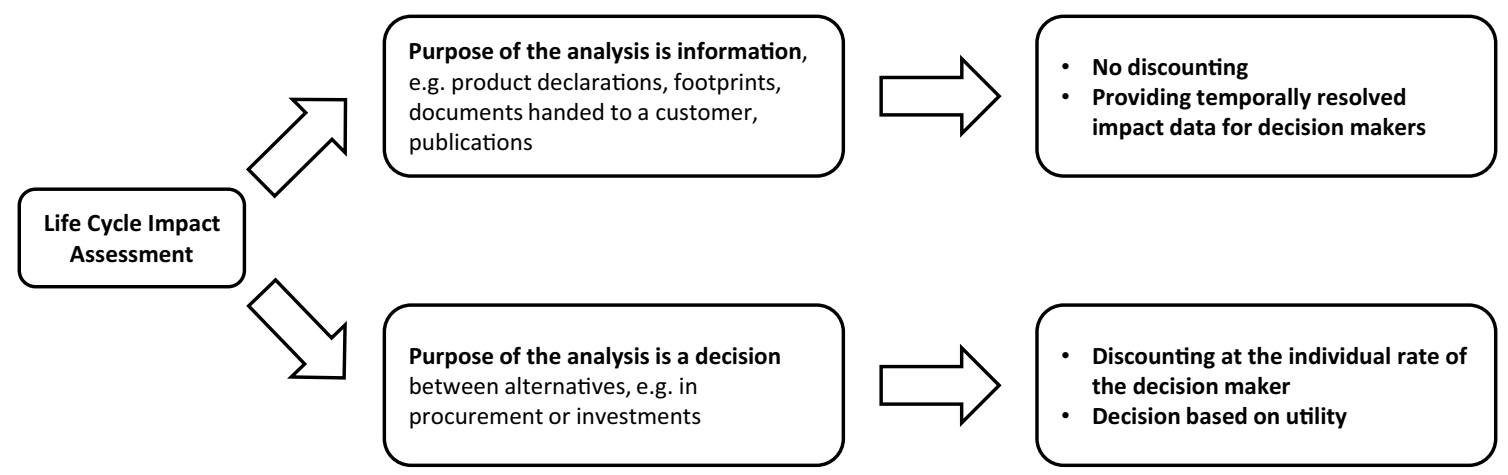

Fig. 4 Decision tree for the application of discounting in LCA

because of the growing economic capacities resulting from economic growth would be over before it ever began. A discount rate of zero would negate future economic growth and therefore the creativity of people to invent new goods and services. According to the Hotelling Theorem, the capital-intensive extraction of scarce resources is dependent on the discount rate. A falling discount rate would decrease the costs for extraction and therefore lead to higher extractions, which is not regarded as sustainable.

Perhaps this had provided some clarity about how disregarding discounting would lead to wrong decisions based on unrealistic assumptions. However, discounting in intertemporal decisions is not an easy task, even when considering the financial dimension alone. Research on personal discount rates of consumers shows the high influence of personal factors, many of which the subjects are often not fully aware of. For example, a low age and limited financial knowledge result in high personal discount rates (Lahav et al. 2010). Companies regularly use the weighted average cost of capital (WACC), the average costs of equity and debt, for the derivation of a discount rate (Krüger et al. 2015). For several reasons, a declining discount rate over time can be assumed. Boucher (2012) discussed a discount rate for LCA declining from 3.5 to $1 \%$ after 30 years because of the change from individual to intergenerational discounting after that time, as well as growing uncertainty. Weitzman (1998) stated that exponential discounting would not reflect the real opinion of people regarding the weight of future emissions from a certain point of time on. For example, an event in 300 years would not be less important than an event in 400 years for them. He also proposed a declining discount rate. For long-term impacts, different declining discount rates should be calculated, with the lowest discount rate being applied as the final one. Fearnside (2002b) introduced a "generation weighted index" where the discount rate declines after every generation for four generations.

\section{Limitations}

Our perception of the literature about environmental discounting results from an intensive preoccupation with temporal issues in LCA for several years. There may be further literature on environmental discounting in other environmental assessment tools that could be extrapolated to LCA. Specifically, cost benefit analysis and economic literature in general might provide more insights for discounting, while this publication is written from a business research perspective.

\section{Conclusion and outlook}

\section{Practical implications}

We illustrated and explained the difficulties and controversies in the field of discounting in LCA. Using two examples from the literature, we showed that discounting can be very decisive for the outcome of environmental decisions. The decision of the application of discounting cannot be avoided. A decision for a discount rate of $0 \%$ is also a decision that should be based on sound reasoning. We further showed that the understanding of discounting in LCA is partly controversial when compared with the original discounted utility model. We conclude that discounting is a reasonable instrument for helping to make intertemporal decisions between certain options which have a different temporal distribution of costs and benefits-including environmental ones, too. Discounting on the other hand should not weaken temporal environmental information before a decision has to be made. In other words, it should only be applied in environmental decision instruments, but not in environmental information instruments (see Fig. 4). Therefore, it is essential that temporally differentiated impact data is provided by LCA to enable discounting. 


\section{Scientific implications}

Unless we regard discounting as beneficial for decision processes, we did not find any good advice for LCA practitioners and decision makers on how to perform that on environmental data. Future scientific work should provide a framework for discounting environmental impacts to support environmental decisions of organizations. Yuan et al. (2015) provided a framework for discounting but concentrated on the generation of a temporally differentiated, "discountable" inventory. To our knowledge, a framework for the derivation of the discount function is missing. We recommend considering a declining discount function (hyperbolic discounting) for long time horizons and considering individual rights to utilize parts of the natural capital (as equity) and emission rights "borrowed" from others, especially from future generations (debt), analogue to the WACC for financial capital. Ethical questions about discounting may be discussed further. We showed reasons why discounting should not be considered unethical, because (1) in our opinion the definition of sustainable development concedes a certain degree of time preference, (2) discarding time preference would disregard the human nature and would lead to decisions that are not accepted, (3) discarding time preference leads to logical dilemmas, (4) opportunity costs and economic growth should be considered in meaningful decisions. Discounting is the appropriate tool to address that.

Acknowledgements We thank BASF SE and Technische Universität Dresden PRISMA - Centre for Sustainability Assessment and Policy for enabling this research by granting a $\mathrm{PhD}$ scholarship.

Funding Open Access funding enabled and organized by Projekt DEAL. The research was supported by a Ph.D-scholarship funded by BASF SE.

Availability of data and material Reviewed literature is publically available.

\section{Declarations}

Conflict of interest The authors declare that they have no conflict of interest.

Open Access This article is licensed under a Creative Commons Attribution 4.0 International License, which permits use, sharing, adaptation, distribution and reproduction in any medium or format, as long as you give appropriate credit to the original author(s) and the source, provide a link to the Creative Commons licence, and indicate if changes were made. The images or other third party material in this article are included in the article's Creative Commons licence, unless indicated otherwise in a credit line to the material. If material is not included in the article's Creative Commons licence and your intended use is not permitted by statutory regulation or exceeds the permitted use, you will need to obtain permission directly from the copyright holder. To view a copy of this licence, visit http://creativecommons.org/licenses/by/4.0/.

\section{References}

Almeida J, Degerickx J, Achten WM, Muys B (2015) Greenhouse gas emission timing in life cycle assessment and the global warming potential of perennial energy crops. Carbon Manage 6(5/6):185-195

Arrow KJ, Cline WR, Mäler K-G, Squitieri R, Stiglitz JE (1996) Intertemporal equity dis-counting and economic efficiency. In: Bruce JP, Haites EF (eds) Economic and social dimensions of climate change. Cambridge University Press, Cambridge

Bakas I, Hauschild MZ, Astrup TF, Rosenbaum RK (2015) Preparing the ground for an operational handling of long-term emissions in LCA. Int J Life Cycle Assess 20(10):1444-1455

Boucher O (2012) Comparison of physically- and economically-based CO2-equivalences for methane. Earth Syst Dyn 3(1):49-61

Brandão M, Levasseur A (2010) Assessing temporary carbon storage in life cycle assessment and carbon footprinting. JRC scientific and technical reports. Joint Research Centre Institute for Environment and Sustainability, Ispra

Brandão M, Levasseur A, Kirschbaum M, Weidema BP, Cowie AL, Jørgensen SV, Hauschild MZ, Pennington DW, Chomkhamsri K (2013) Key issues and options in accounting for carbon sequestration and temporary storage in life cycle assessment and carbon footprinting. Int J Life Cycle Assess 18(1):230-240

Cherubini F, Guest G, Strømman AH (2012) Application of probability distributions to the modeling of biogenic $\mathrm{CO} 2$ fluxes in life cycle assessment. GCB Bioenergy 4(6):784-798

Collinge WO, Landis AE, Jones AK, Schaefer LA, Bilec MM (2013) Dynamic life cycle assessment. Framework and application to an institutional building. Int J Life Cycle Assess 18(3):538-552

Constanza R, Daly HE (1992) Natural capital and sustainable development. Conserv Biol 6(1):37-46

Fearnside PM (2002a) Why a 100-year time horizon should be used for globalwarming mitigation calculations. Mitig Adapt Strateg Glob Change 7:19-30

Fearnside PM (2002b) Time preference in global warming calculations: a proposal for a unified index. Ecol Econ 2002(41):21-31

Fearnside PM, Lashof DA, Moura-Costa P (2000) Accounting for time in mitigating global warming through land-use change and forestry. Mitig Adapt Strateg Glob Change 5(3):239-270

Field F, Kirchain R, Clark J (2001) Life-cycle assessment and temporal distributions of emissions: developing a fleet-based analysis. J Ind Ecol 4(2):71-91

Frederick S, Loewenstein G, O'donoghue T (2002) Time discounting and time preference a critical review. J Econ Literat 40(2):351-401

Goedkoop M, Spriensma R (1999) The eco-indicator 99 a damage oriented method for life cycle impact assessment methodology report. https://www.pre-sustainability.com/download/EI99_metho dology_v3.pdf

Gowdy J, Rosser JB, Roy L (2013) The evolution of hyperbolic discounting: implications for truly social valuation of the future. $\mathrm{J}$ Econ Behav Organ 90:94-104

Haidt J (2013) The righteous mind. Why good people are divided by politics and religion. Penguin Books, London

Hauschild MZ, Rosenbaum RK, Olsen SI (2018) Life cycle assessment. Theory and practice. Springer, Cham

Held M (2016) Sustainable development from a temporal perspective. Time Soc 10(2-3):351-366

Hellweg S, Hofstetter TB, Hungerbühler K (2003) Discounting and the environment should current impacts be weighted differently than impacts harming future generations? Int J LCA 8(1):8-18

Hellweg S, Hofstetter TB, Hungerbühler K (2005) Time-dependent life-cycle assessment of slag landfills with the help of scenario analysis. The example of $\mathrm{Cd}$ and Cu. J Clean Prod 13(3):301-320 
Herrchen M (1998) Perspective of the systematic and extended use of temporal and spatial aspects in LCA of long-lived products. Chemosphere 37(2):265-270

Herzog H, Caldeira K, Reilly JM (2003) An issue of permanence: assessing the effectiveness of temporary carbon storage. Clim Change 59:293-310

Hofstede G, Hofstede GJ, Minkov M (2010) Cultures and organizations. Software of the mind: intercultural cooperation and its importance for survival, Revised and expanded 3rd edn. McGrawHill, New York

Hofstetter P, Baumgartner T, Scholz RW (2000) Modelling the valuesphere and the ecosphere. Integrating the decision makers' perspectives into LCA. Int J LCA 5(3):161-175

Hu M (2018) Dynamic life cycle assessment integrating value choice and temporal factors-a case study of an elementary school. Energy Build 158:1087-1096

Huijbregts M, Steinmann Z, Elshout PMF, Stam G, Verones F, Vieira MDM, Hollander A, Zijp M, van Zelm R (2017) ReCiPe 2016 v1.1 a harmonized life cycle impact assessment method at midpoint and endpoint level report I: characterization. RIVM Report 2016-0104a. https://www.pre-sustainability.com/download/ Report_ReCiPe_2017.pdf. Accessed 13 Apr 2020

Illés M (2014) Fisher's rate and aggregate capital needs in investment decisions. Club Econ Miskolc TMP 10(1):21-32

Kallis G, Gómez-Baggethun E, Zografos C (2015) The limits of monetization in valuing the environment. Ecol Econ 112:170-173

Kendall A, Chang B, Sharpe B (2009) Accounting for time-dependent effects in biofuel life cycle greenhouse gas emissions calculations. Environ Sci Technol 43(18):7142-7147

Krüger P, Landier A, Thesmar D (2015) The WACC fallacy: the real effects of using a unique discount rate. J Financ 70(3):1253-1285

Lahav E, Benzion U, Shavit T (2010) Subjective time discount rates among teenagers and adults: evidence from Israel. J Soc-Econ 39(4):458-465

Landy FJ, Conte JM (2016) Work in the 21st century. An introduction to industrial and organizational psychology, 5 th edn. Wiley binder version, Wiley, Hoboken

Lebailly F, Levasseur A, Samson R, Deschênes L (2014) Development of a dynamic LCA approach for the freshwater ecotoxicity impact of metals and application to a case study regarding zinc fertilization. Int J Life Cycle Assess 19(10):1745-1754

Levasseur A, Lesage P, Margni M, Brandão M, Samson R (2012) Assessing temporary carbon sequestration and storage projects through land use, land-use change and forestry. Comparison of dynamic life cycle assessment with ton-year approaches. Clim Change 115(3/4):759-776

Levine SH, Gloria TP, Romanoff E (2007) A dynamic model for determining the temporal distribution of environmental burden. J Ind Ecol 11(4):39-49
Lueddeckens S, Saling P, Guenther E (2020) Temporal issues in life cycle assessment-a systematic review. Int J LCA 6(5/6):185

Macháč J, Trantinová M, Zaňková L (2021) Externalities in agriculture: how to include their monetary value in decision-making? Int $\mathrm{J}$ Environ Sci Technol 18:3-20

Mallapragada D, Mignone BK (2017) A consistent conceptual framework for applying climate metrics in technology life cycle assessment. Environ Res Lett 12(7):074022

O'Hare M, Plevin RJ, Martin JI, Jones AD, Kendall A, Hopson E (2009) Proper accounting for time increases crop-based biofuels' greenhouse gas deficit versus petroleum. Environ Res Lett 4(2):24001

Patouillard L, Bulle C, Querleu C, Maxime D, Osset P, Margni M (2018) Critical review and practical recommendations to integrate the spatial dimension into life cycle assessment. J Clean Prod 177:398-412

Reuer JJ, Tong TW (2007) Real options theory. Advances in strategic management $0742-3322$ v. 24 . Bingley, Emerald

Richards KR (1997) The time value of carbon in bottom-up studies. Crit Rev Environ Sci Technol 27(sup001):279-292

Saurat M, Ritthoff M, Smith L (2015) Sustainability assessment methods and tools to support decission-making in the process industries Deliverable 1.1. Wuppertal Institut

Schwartz SH (2007) Value orientations: measurement, antecedents and consequences across nations. In: Jowell R (ed) Measuring attitudes cross-nationally. Lessons from the European Social Survey. SAGE, Los Angeles, pp 169-203

Temel J, Jones A, Jones N, Balint L (2018) Limits of monetization in protecting ecosystem services. Conserv Biol: J Soc Conserv Biol 32(5):1048-1062

Udo de Haes HA, Jolliet O, Finnveden G, Hauschild M, Krewitt W, Müller-Wenk R (1999) Best available practice regarding impact categories and category indicators in life cycle impact assessment. Int J LCA 4(3): 167-174

United Nations (2015) MY World Survey 2015. http://data.mywor ld2015.org/? Accessed 12 May 2020

Wang J, Zhang Y, Wang Y (2018) Environmental impacts of short building lifespans in China considering time value. J Clean Prod 203:696-707

Weitzman ML (1998) Why the far-distant future should be discounted at its lowest possible rate. J Environ Econ Manage 36(3):201-208

Yuan C, Wang E, Zhai Q, Yang F (2015) Temporal discounting in life cycle assessment. A critical review and theoretical framework. Environ Impact Assess Rev 51:23-31

Yuan CY, Simon R, Mady N, Dornfeld D (2009) Embedded temporal difference in life cycle assessment. Case study on VW golf A4 car. In: IEEE 2009 ieee international symposium on sustainable systems and technology 